\title{
Poly(Methacryloiloxy-o-Benzoic Acid) as Drug Carrier for Controlled Release
}

Víctor Gómez-Reséndiz, Aracely Serrano-Medina, Eugenia Gabriela Carrillo-Cedillo, Manuel Cornejo, and José Manuel Cornejo-Bravo*

Facultad de Ciencias Químicas e Ingeniería. Universidad Autónoma de Baja California. Calzada Universidad 14418, Parque Industrial Internacional, Tijuana, B.C. C.P. 22390.jmcornejo@uabc.edu.mx

Received April 10th, 2014; Accepted June 17th, 2014

\begin{abstract}
Poly(methacryloiloxy-o-benzoic acid), an amphiphilic weak polyelectrolyte was bound by secondary forces to cationic drugs (propranolol $\mathrm{HCl}$ and labetalol $\mathrm{HCl})$ to form water-insoluble complexes that release the bound drug only in ionic media. Compressed tablets were prepared from the polymer-drug complexes formed. The complex with propranolol suffers a fast release in simulated gastric fluid (pH 1.2), but presents a diffusion controlled release at $\mathrm{pH} 6.8$ and 7.4. Moreover, the complex with labetalol (a less water soluble drug) presents controlled release at the three $\mathrm{pH}$ values studied. In this case, release is controlled by the erosion of the tablets. The results indicate that PMAOB is a good carrier for oral release of poorly soluble cationic drugs.

Keywords: Polyelectrolyte, amphiphilic, sustained drug release, ion exchange.
\end{abstract}

\section{Introduction}

Polyelectrolytes have been extensively studied as carriers for oppositely charged drugs with drug release occurring by ionic exchange. Most applications use ion exchange resins (reticulated polymers) where drug release is affected by the swelling of the networks resulting in Fickian kinetics (square-root-time dependency) with severe tailing toward the end of the drug release process [1-6]. On the other hand, drug release from complexes with linear polyelectrolytes produces pseudo-zero order release when synchronism occurs between drug ion exchange and erosion of the soluble, ion exchanged, polymer chains [7-16].

Polyelectrolytes bearing weak acid groups (anionic) can form complexes with drugs containing amine moieties (cationic) according to the scheme

$$
\mathrm{PCOO}^{-}+{ }^{+} \mathrm{NH}_{3}-\mathrm{D} \rightarrow \mathrm{P}-\mathrm{COO}^{-+} \mathrm{NH}_{3}-\mathrm{D}
$$

When these complexes are administered orally the drug is released by an ionic exchange process as shown in the following schemes:

In the stomach:

$$
\mathrm{P}-\mathrm{COO}^{-+} \mathrm{NH}_{3}-\mathrm{D}+\mathrm{HCl} \rightarrow \mathrm{P}-\mathrm{COOH}+{ }^{+} \mathrm{NH}_{3}-\mathrm{D}
$$

In the intestine:

$$
\mathrm{P}-\mathrm{COO}^{-+} \mathrm{NH}_{3}-\mathrm{D}+\mathrm{NaCl} \rightarrow \mathrm{PCOO}^{-}+{ }^{+} \mathrm{NH}_{3}-\mathrm{D}
$$

Resumen. El polielectrolito anfifílico poli(ácido metacriloiloxi-obenzoico) fue enlazado, por interacciones secundarias, a fármacos catiónicos (propranolol $\cdot \mathrm{HCl}$ y labetalol $\cdot \mathrm{HCl}$ ) para formar complejos insolubles en agua. Se prepararon comprimidos por compresión directa con los complejos formados. El complejo de propranolol sufre una liberación inmediata en fluido gástrico simulado $(\mathrm{pH} 1.2)$, pero presenta una liberación controlada por difusión a pH 6.8 y 7.4. Por otra parte, el complejo con labetalol (un fármaco menos soluble en agua) presenta liberación sostenida en los tres valores de $\mathrm{pH}$ evaluados. En este caso la liberación del fármaco es controlada por la erosión de los comprimidos. El resultado indica qué ácido es un buen acarreador para la liberación de fármacos catiónicos muy poco solubles, administrados por vía oral.

Palabras clave: Polielectrolito, amfifílico, liberación sostenida, intercambio iónico.

Polyelectrolytes used have to be amphiphilic so the complexes formed are insoluble in pure water and can be recovered upon formation, and the hydration of the complexes in the pharmaceutical forms is slow to attain extended release.

Most studies use copolymers of an ionogenic monomer with a non-ionizable, hydrophobic one (e.g. methyl methacrylate) [7-14]. Copolymerization with a non-ionizable monomer brings some disadvantages. It reduces the drug-polyelectrolyte interaction, possibly decreasing the loading capacity of the polyelectrolyte. Furthermore, copolymers require composition characterization for each polymerization batch, and due to differences on the reactivity ratio between monomers it is difficult to obtain the desired composition [10].

These disadvantages can be overcome by using homopolymers as carriers which bear amphiphilic repetitive units, formed by a hydrophobic spacer and an ionizable carboxylic acid moiety $[15,16]$. It has been observed that drug release from these materials is not only dependent on the ionic strength of the medium, but also on the $\mathrm{pH}$, giving them potential for drug delivery at specific sites of the gastrointestinal tract (e.g. colon-specific delivery), considering the local differences on $\mathrm{pH}$ through the digestive tube $[17,18]$.

Previously we developed a facile method to produce a methacrylate derivative of salicylic acid which has been polymerized to prepare an amphiphilic aromatic polyelectrolyte: poly(metacryloyloxi-o-benzoic acid) (PMAOB) (Figure 1) [19]. In this work we study the potential of PMAOB as carrier for antihypertensive drugs: propranolol and labetalol (Figure 2). 


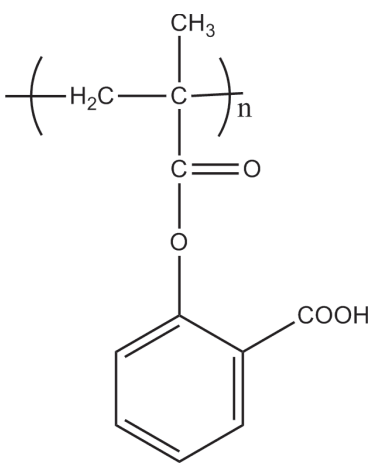

Fig. 1. Structure of PMAOB.

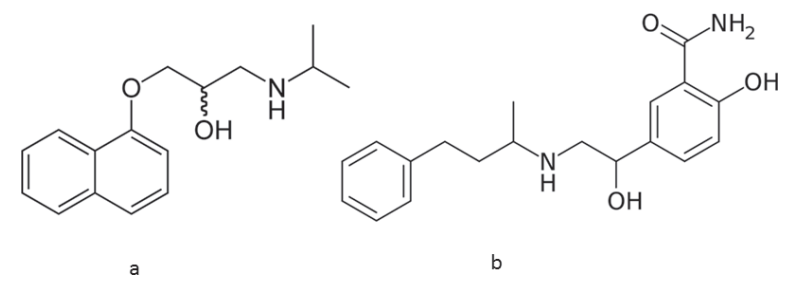

Fig. 2. Structures of a) propranolol, and b) labetalol.

\section{Results and discussion}

\section{Drug-Polymer complexes formation and characterization}

PMAOB is a vitreous polymer with a reported glass transition temperature of $130{ }^{\circ} \mathrm{C}$ [19]. The measured molecular weight was $522,000 \mathrm{~g} / \mathrm{mol}$.

When a solution containing the potassium salt of PMAOB was poured into an excess of drug (hydrochloride form) solution, a water insoluble complex formed in the two cases studied (propranolol and labetalol). Evidence of complex formation between the drug and the polymer was furnished by FTIR studies. Shown in Figure 3 is the FTIR spectrum of the PMAOBpropranolol complex. The absorption band around $1556 \mathrm{~cm}^{-1}$ in the spectrum of the complex is assigned to the vibration of the carboxylate group of the polymer ion involved in the complexation with the amine group of the drug. An absorption band around $1397 \mathrm{~cm}^{-1}$ is assigned to the stretching of the

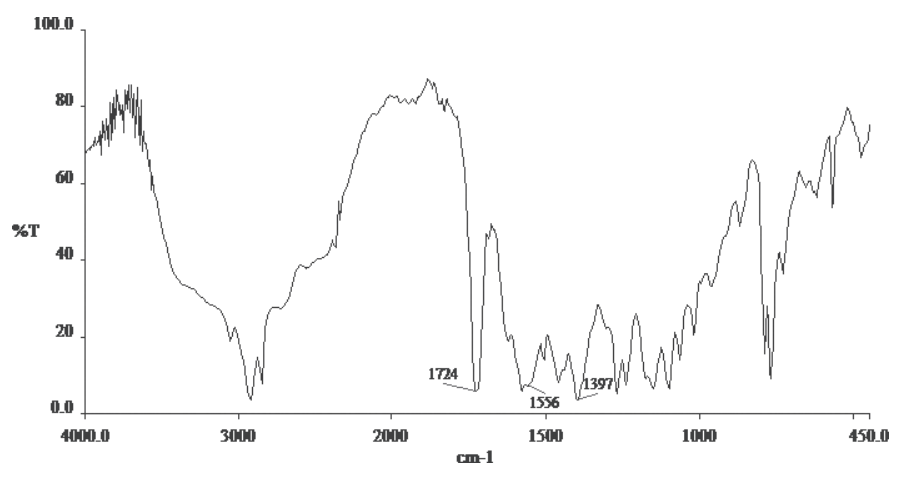

Fig. 3. FTIR spectrum of the PMAOB-propranolol complex.
$\mathrm{C}-\mathrm{N}$ bond in propranolol. The absorption band around 1724 $\mathrm{cm}^{-1}$ corresponds to the carbonyl in the ester group of the polyelectrolyte.

The FTIR spectrum of the PMAOB-labetalol complex is shown in Figure 4. It shows the same absorption bands observed for the PMAOB-propranolol complex.

Table 1 summarizes the physicochemical properties of the drugs. The drug loading in the complexes prepared and the expected loading, considering that each carboxyl group is attached to one drug molecule by an ionic bond, are presented in Table 2. Loadings are lower than the expected by ionic interactions for the MAOB-propranolol complex but higher than expected for PMAOB-labetalol complex; probably due to additional hydrophobic interactions between drug and polymer since labetalol is a much less water soluble than propranolol. Similar results have been reported for polyelectrolytes containing hydrophobic domains [20-22].

\section{Solubility studies}

Table 3 presents the water solubility of the polymer and the complexes at different $\mathrm{pH}$ values. PMAOB is poorly soluble at $\mathrm{pH} 1.2$, with a slight increase as the $\mathrm{pH}$ increases.

Table 1. Physicochemical properties of drugs used in this study.

\begin{tabular}{lcccc}
\hline \multicolumn{1}{c}{ Drug } & $\begin{array}{c}\text { Mw } \\
(\mathrm{g} / \mathrm{mol})\end{array}$ & $\mathrm{pKa}$ & $\begin{array}{c}\text { Solubility free } \\
\text { base }(\mathrm{mg} / \mathrm{L})^{[23]}\end{array}$ & $\begin{array}{c}\text { Solubility } \\
\text { hydrochloride } \\
(\mathrm{g} / \mathrm{L})^{[24]}\end{array}$ \\
\hline Propranolol & 259.35 & 9.5 & 79.40 & 97.96 \\
Labetalol & 328.41 & 9.3 & 5.78 & 18.29 \\
\hline
\end{tabular}

Table 2. Content of the complexes.

\begin{tabular}{lcc}
\hline \multicolumn{1}{c}{ Complex } & $\begin{array}{c}\text { Expected drug } \\
\text { loading } \mathrm{w} \%\end{array}$ & $\begin{array}{c}\text { Real drug loading } \\
\mathrm{w} \%\end{array}$ \\
\hline PMAOB-propranolol & 58.94 & 49.79 \\
PMAOB-labetalol & 63.91 & 76.26 \\
\hline
\end{tabular}

Table 3. Solubility studies of polymer and complexes.

\begin{tabular}{lccc}
\hline \multicolumn{1}{c}{ Substance } & $\mathrm{pH}$ & $\begin{array}{c}\text { Solubilidad } \\
(\mathrm{mg} / \mathrm{mL})\end{array}$ & $\begin{array}{c}\text { Drug concentration in } \\
\text { supernatant }(\mathrm{mg} / \mathrm{mL})\end{array}$ \\
\hline PMAOB & 1.2 & 4.58 & \\
& 6.8 & 7.42 & \\
& 7.4 & 9.29 & 66.86 \\
PMAOB-propranolol & 1.2 & 125.0 & \\
complex & & & 4.25 \\
& 6.8 & 6.3 & 4.19 \\
& 7.4 & 7.0 & 2.74 \\
PMAOB-labetalol & 1.2 & 5.39 & 2.58 \\
complex & & & 2.18 \\
& 6.8 & 3.78 & \\
& 7.4 & 3.29 & \\
\hline
\end{tabular}




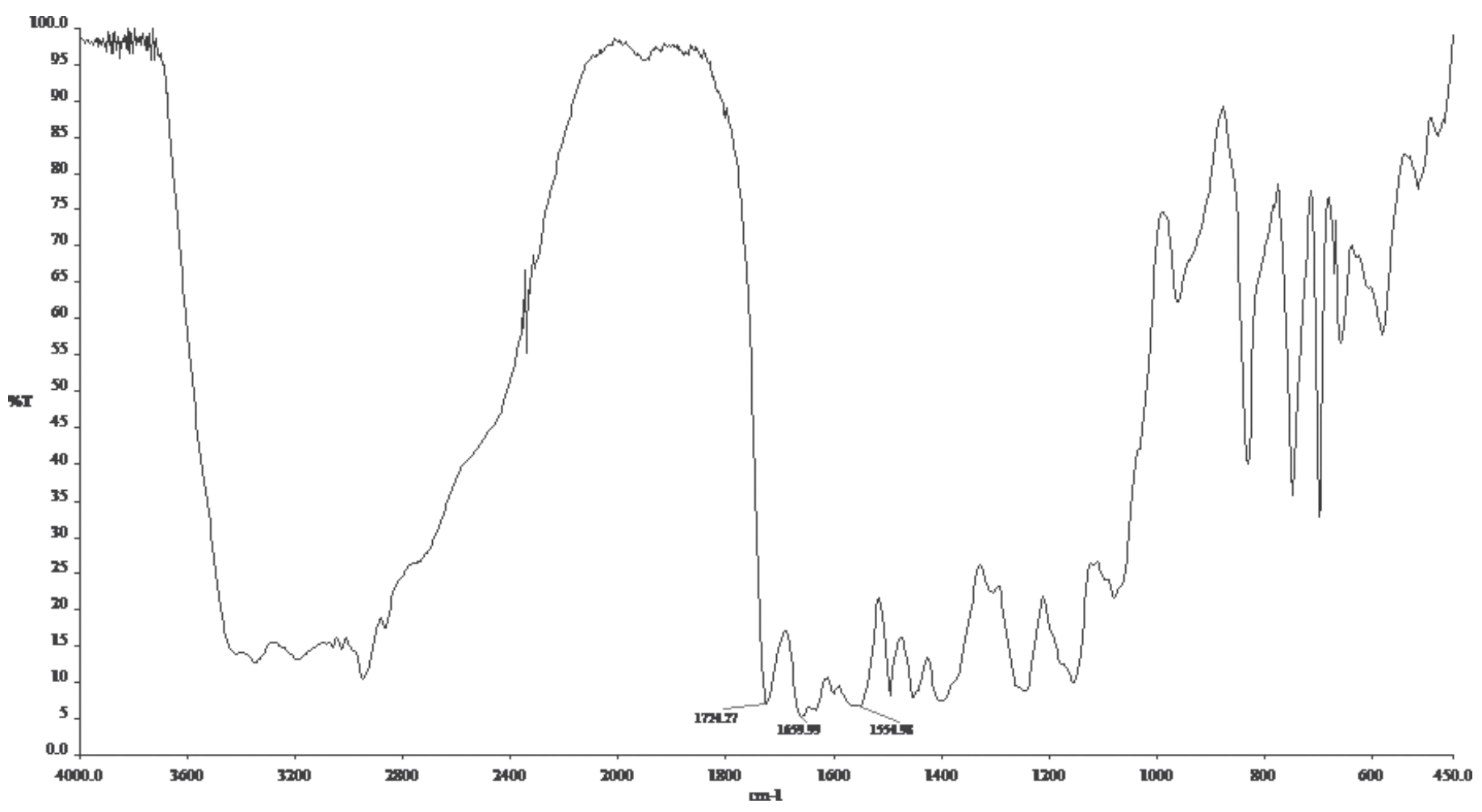

Fig. 4. FTIR spectrum of the PMAOB-labetalol complex.

According to the reported titration curve for PMAOB the $\mathrm{pK}_{\mathrm{a}(\mathrm{app})}(\mathrm{pH}$ of the solution at $50 \%$ ionization) is 5.8 [19]. High ionization at $\mathrm{pH} 6.8$ and 7.4 explains the increase on solubility at these $\mathrm{pH}$ values. However the increase in solubility with $\mathrm{pH}$ is slight due to the amphiphilic nature of the polymer and the formation of intramolecular bonds between the carboxylic acid group and the ester group of the methacrylate. The solubility of the PMAOB-propranolol complex at $\mathrm{pH} 1.2$ is considerably higher than for the polymer. At this $\mathrm{pH}$ it is expected that PMAOB exists in the un-ionized form when propranolol is expected to exist in the ionized form (pKa 9.5). These conditions may lead to the breakdown of the complex. However the solubility of the complex seems to exceed the solubility of the polymer and propranol (as the hydrochloride). Due to the intriguing nature of the results, we decided to analyze the supernatant by dynamic light scattering (DLS). A nanometric structure of 166 $\mathrm{nm}$ was observed. The structure had a monomodal distribution with a polydispersity (PDI) of 0.006 (Figure 5).

We hypothesize that the ionized form of propranolol emulsifies the polymer, increasing its solubility by forming a stabilized nanoestructure. Propranolol may interact with PMAOB trough $\pi-\pi$ bonds. The supernatant of the solutions at $\mathrm{pH} 6.8$ and 7.4 did not present nanometric structures. At these $\mathrm{pH}$ values both polymer and drug are at the ionized state so the rupture of the complex only occurs by ionic exchange with the ions of the media.

On the other hand the solubility of PMAOB-labetalol complex is low at any $\mathrm{pH}$. The supernatant of the solution did not present a nanoparticulate matter. Apparently labetalol does not have the ability to solubilize the polymer chains due to its low water solubility. The structure of the two drugs may also account for the differences found at low $\mathrm{pH}$ : propranolol has the aromatic groups in one side of the molecule while the amine group is at the other end (see Figure 2). If the aromatic groups interact with the polymer the drug will point the ionized amine groups toward the aqueous solution, working as an emulsifier. On the other hand, labetalol has the aromatic rings at both sides of the molecule, while the amine group is in the middle of the molecule, so the arrangement proposed in the case of propranolol is not feasible.

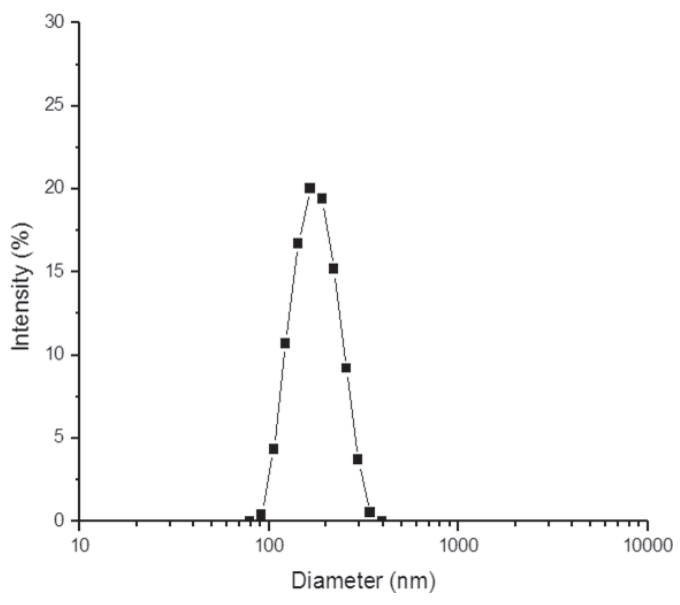

Fig. 5. Size distribution of nanostructures present in the dissolution of the PMAOB-propranolol complex at $\mathrm{pH}$ 1.2. 


\section{Drug release studies}

Drug release from tablets prepared by direct compression of the PMAOB-propranolol complex are presented in Figure 6.

We observe a very fast release at $\mathrm{pH} 1.2$ with the entire drug load released in the first hour. This result is similar to the fast release of drugs in the stomach (dumping) observed with complexes formed by vitreous copolymers of methacrylic (or acrylic) acid and methyl methacrylate. [25-26], which is attributed to the rapid conversion of the carboxylate groups in the polyelectrolytes to the non-ionized form at this $\mathrm{pH}$, releasing the drug in the ionized form. Interestingly, only a small amount of precipitate is observed at the end of the dissolution process. Analysis of the supernant by DLS shows the presence of a nanometric structure similar to the observed in the solubility studies and attributed to the emulsification phenomenon.

At $\mathrm{pH} 6.8$ drug releases is considerable slower with only $15 \%$ released at $12 \mathrm{~h}$. At this $\mathrm{pH}$ propranol is ionized and the polyelectrolyte is mostly ionized so release occurs by ionic exchange. At pH 7.4 drug release is faster with $72 \%$ released at 12 $\mathrm{h}$. The higher rate and, consequently, higher fraction released at any given time with higher $\mathrm{pH}$ can be attributed to the slightly higher ionization of the polyelectrolyte which increases the hydration of the tablets. In medium $\mathrm{pH} 7.4$ an acceleration of the release rate is observed at $8 \mathrm{~h}$ into the release process, which is probably due to the distortion of the tablets, visually observed, caused by high hydration of the material, exposing more area for release. A release experiment was performed at $\mathrm{pH} 6.8$ with $0.3 \mathrm{~N} \mathrm{NaCl}$. A faster rate of release is observed demonstrating that the prevailing release process is ionic exchange. Without $\mathrm{NaCl}$ added, the ionic strength at $\mathrm{pH} 7.4$ is higher than at $\mathrm{pH}$ 6.8 (0.1283 and 0.0975 M, respectively), since both solutions have the same total phosphate buffer concentrations $(0.05 \mathrm{M})$

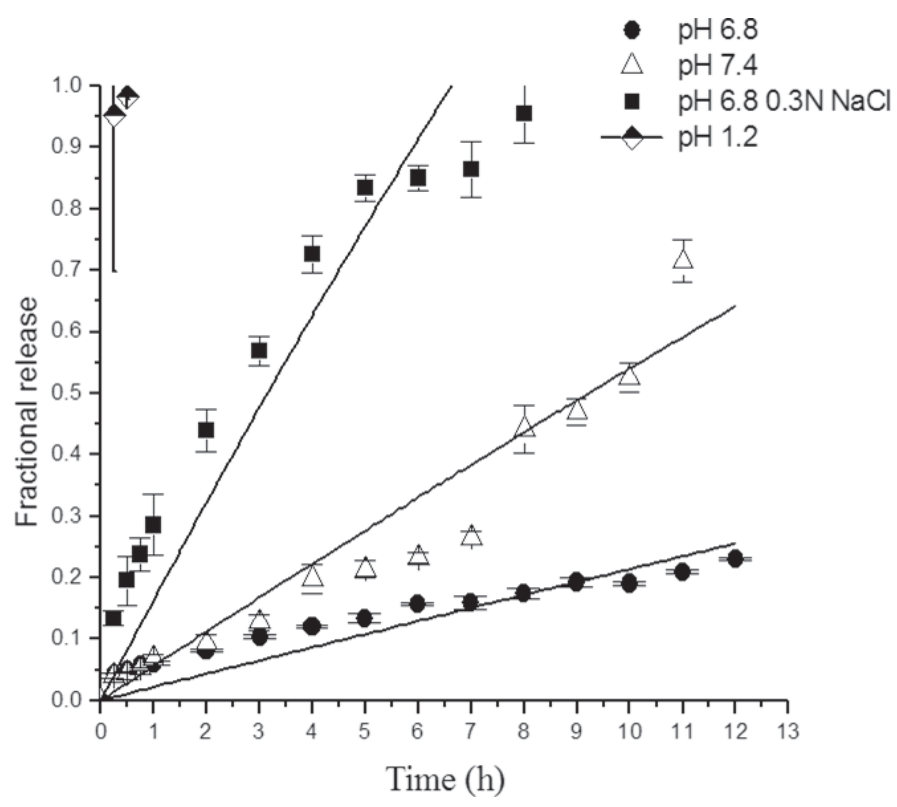

Fig. 6. Drug release kinetics from PMAOB-propranolol complexes. Data fittings according to Eq. (5) are presented as solid lines. but different proportions of the anions $\left(\mathrm{H}_{2} \mathrm{PO}_{4}^{-1}\right.$ and $\left.\mathrm{HPO}_{4}{ }^{-2}\right)$, and dibasic phosphate has a higher contribution to ionic exchange. This can also explain the higher rate of release at $\mathrm{pH}$ 7.4 than at $\mathrm{pH} 6.8$.

Figure 7 presents the rate of release of PMAOB-labetalol complex.

At the three media studied a controlled release is observed. Labetalol is less soluble than propranolol in both free base and hydrochloride form and does not produce the emulsification observed with propranolol. Labetalol $(\mathrm{pKa}=9.3)$ is mostly ionized at the $\mathrm{pH}$ values studied; for instance, drug is released as the ionized form of the molecule (more soluble). Breakdown of the complex is expected at $\mathrm{pH} 1.2$ due to the conversion of PMAOB to the acid form. However, due to the slow hydration of the complex release occurs in a controlled fashion. At $\mathrm{pH}$ 6.8 and 7.4 both drug and polyelectrolyte are mostly ionized and release occurs by ionic exchange. The higher ionization of labetalol at $\mathrm{pH} 6.8$ than at $\mathrm{pH} 7.4$ may account for the faster release observed at $\mathrm{pH} 6.8$ than at $\mathrm{pH}$ 7.4. In this case, the increase in solubility of the drug at lower $\mathrm{pH}$ has a higher impact on the rate of release than the increase in solubility of the polyelectrolyte at higher $\mathrm{pH}$; contrary to the observed for propranolol.

The linearity of drug release was assessed by fitting the release data, up to $80 \%$ release, to the phenomenological equation [27]:

$$
\frac{M_{t}}{M_{\infty}}=k t^{n} \quad \text { or } \quad \ln \left(\frac{M_{t}}{M_{\infty}}\right) n \ln (t)+\ln (k)
$$

The terms in this equation are as follows: $\mathrm{M}_{\mathrm{t}}$, the amount of drug released at time $t ; \mathrm{M}_{\infty}$, the amount released at $t=\infty ; k$ the kinetics constant; and $n$, the mechanism of drug release. The value of $n$ ranges from $0.5\left(t^{1 / 2}\right.$ dependence, generally referred to as Fickian release) to 1 (representing the case-II or non-Fickian transport which is purely relaxation controlled). The values in between indicate an anomalous behavior corresponding to coupled diffusion/relaxation.

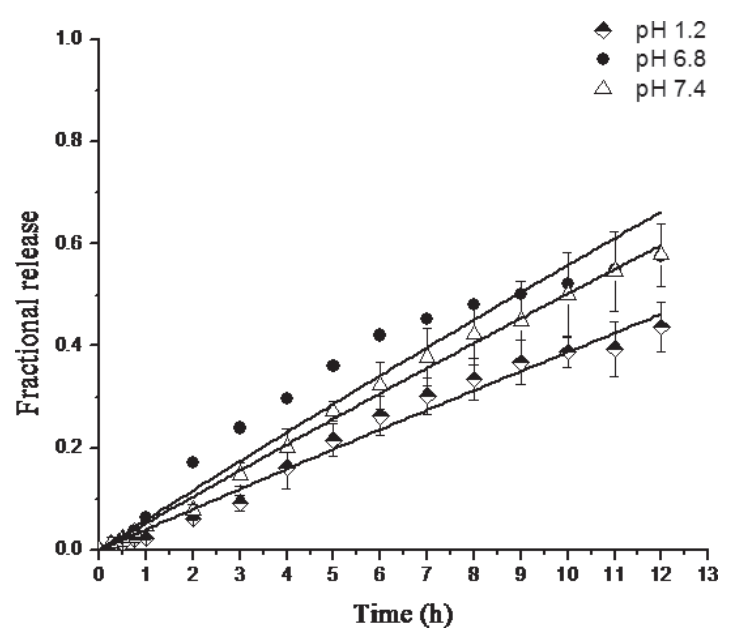

Fig. 7. Drug release kinetics from PMAOB-labetalol complexes. Solid lines are from data fitting according to Eq. (5). 
The dissociation/erosion mechanism of the drug release kinetics was evaluated using the following equation [7]:

$$
\frac{M_{t}}{M_{\infty}}=1-\left(1-\frac{k_{c} t}{C_{o} r_{o}}\right)^{L}\left(1-\frac{2 k_{c} t}{C_{o} l}\right)
$$

where $k_{e}, C_{o}, r_{o}$ and $l$ are the dissociation/erosion rate constant, the initial drug concentration in a tablet, the tablet radius, and the tablet thickness, respectively.

The results of the correlation using Eq.(4) are presented in Table 4. The results indicate that release of propranolol at $\mathrm{pH}$ 6.8 (with and without added $\mathrm{NaCl}$ ) is controlled by diffusion, when at $\mathrm{pH} 7.4$ the results show an anomalous behavior from coupling of diffusion and a non-Fickian release. Otherwise, drug release form the PMAOB-labetalol complex is controlled by a non-Fickian mechanism at the three $\mathrm{pH}$ values studied. The dissociation/erosion constant $\left(k_{e}\right)$ of the drug complexes was determined using a nonlinear regression analysis (PRISM, GraphPad Sofware, Inc, San Diego CA) of Eq. (5). The results are also presented in Table 4. Data fitting to this equation (up to $90 \%$ release) are also presented in Figures 6 and 7. Drug release kinetics was not accurately predicted by Eq. (5) for propranol. Predictions underestimate the release indicating that ionic exchange is faster than chain erosion; besides, acceleration on the release process due to distortion of the tables is not accounted by the Eq.(5). Underestimation of drug release also occurs for the PMAOB-labetalol complex at $\mathrm{pH}$ 6.8. Otherwise, drug release kinetics were accurately predicted by Eq. (5) for the complexes with labetalol at $\mathrm{pH} 1.2$ and 7.4.

Rate of release are similar for propranolol and labetal$\mathrm{ol}$ at $\mathrm{pH}$ 7.4. This result is similar to those reported using strong polyelectrolytes [11], but differ to the observed with poly(alkylmethacrylates) which are plastic materials at $37{ }^{\circ} \mathrm{C}$ [15-16].

\section{Experimental}

\section{Reagents and materials}

USP-grade propranolol $\cdot \mathrm{HCl}$ and labetalol $\cdot \mathrm{HCl}$ were from Spectrum Chemical Co. (Gardena, CA, USA). All other chemicals and solvents used were obtained either from Aldrich Chemicals or from Productos Químicos Monterrey.

\section{Polymer preparation}

Methacryolyoxy-o-benzoic acid and its polymer, PMAOB, were prepared according to a previously reported method [19]. Molecular weight of the polymer was determined by static light scattering, using a Zetasizer Nano-ZS, Malvern Instruments (Southborough MA). The Debye plot was obtained with concentrations between 0.2 and $1 \mathrm{mg} / \mathrm{mL}$ in methanol. The $\mathrm{dn} / \mathrm{dc}$ parameter was $0.0901 \mathrm{~mL} / \mathrm{g}$, obtained with a Refractive Index detector (Optilab T-rex, Wyatt Technology), using the same wavelength as the Zetasizer Nano-Zs (532 nm). Toluene was used as the standard.

PMAOB was converted to the corresponding potassium salts by neutralizing a methanolic solution of the polymer with an equimolar amount of $\mathrm{KOH}$ in methanol. The polymeric salt was precipitated and washed with ethyl ether, then dried under vacuum at $40{ }^{\circ} \mathrm{C}$ for five days.

\section{Drug-polyelectrolyte complex preparation and characterization}

An excess amount of drug solution (1.5 the mole ratio of drug to polyelectrolyte) was added to an aqueous solution of PMAOB (potassium salt) to obtain a precipitated drug-polyelectrolyte complex. It was then thoroughly washed with distilled water and dried under vacuum. The dried drug-polymer complexes were pulverized in a mortar with pestle, followed by screening through a 100 mesh sieve.

The FTIR spectrum (Perkin-Elmer 1600) of the complexes was obtained using the $\mathrm{KBr}$ tablet method.

The content of drug in each complex was then determined. Dissolution of each complex in $1 \mathrm{M}$ phosphate, $\mathrm{pH} 7.4$, was followed by filtration through a $0.22 \mu \mathrm{m}$ syringe filter, then measuring the concentration by HPLC.

Tablets containing $200 \mathrm{mg}$ of the complex were compressed using a $13 \mathrm{~mm}$ diameter die in a Carver press (Wabash, IN) with a compression force of $2500 \mathrm{~kg}$. Tablets of about 1.3 $\mathrm{mm}$ thickness were obtained.

Table 4. Dissociation/erosion rate constants and regression parameters of the release studies performed.

\begin{tabular}{|c|c|c|c|c|c|}
\hline & $\begin{array}{c}n \\
\text { (Eq. 4) }\end{array}$ & $\begin{array}{c}\text { Kinetic constant } \\
(k, \text { Eq. } 4)\end{array}$ & $\mathrm{R}^{2}$ (Eq. 4) & $\begin{array}{l}\text { Dissociation/erosion } \\
\text { rate constant } \\
\left(\mathrm{k}_{\mathrm{e}}, \text { Eq. } 5\right) \mathrm{mg} / \mathrm{cm}^{2} \mathrm{~h}\end{array}$ & $\begin{array}{c}\mathrm{R}^{2} \\
\text { (Eq. 5) }\end{array}$ \\
\hline Propranolol pH 6.8 & 0.5184 & 0.0808 & 0.992 & 0.6402 & 0.8120 \\
\hline Propranolol pH 7.4 & 0.7843 & 0.0741 & 0.9309 & 1.668 & 0.9371 \\
\hline $\begin{array}{l}\text { Propranolol pH } 6.8 \\
0.3 \mathrm{~N} \mathrm{NaCl}\end{array}$ & 0.6056 & 0.2955 & 0.9958 & 4.881 & 0.8773 \\
\hline Labetalol pH 6.8 & 1.0817 & 0.0529 & 0.9689 & 1.727 & 0.9428 \\
\hline Labetalol pH 7.4 & 1.0255 & 0.0477 & 0.996 & 1.546 & 0.9962 \\
\hline
\end{tabular}




\section{Solubility Studies}

The solubility of polymer and complexes was studied in simulated gastric solution $(\mathrm{pH} 1.2,[\mathrm{NaCl}]=0.057 \mathrm{M})(27$ US Pharmacopeia, 2004), simulated intestinal solution pH $6.8(0.05 \mathrm{M}$ phosphate buffer) and simulated colonic solution $\mathrm{pH} 7.4(0.05 \mathrm{M}$ phosphate buffer). The polymer or the complexes were added to a fixed volume of media at $37^{\circ} \mathrm{C}$ until a saturated solution was obtained. The solutions were stirred for $72 \mathrm{~h}$. The undissolved material was recovered by centrifugation, dried and weighted to calculate the solubility of the material. For the complexes, the drug concentration on the supernatant was determined by HPLC. The supernatant was analyzed by DLS using Zetasizer Nano-ZS.

\section{Drug release kinetics}

The release kinetics from tablets of the drug-polymer complexes were carried out at $37^{\circ} \mathrm{C}$ in $900 \mathrm{~mL}$ of simulated gastric media, simulated intestinal media $\mathrm{pH} 6.8$ with and without added $\mathrm{NaCl}$, or $\mathrm{pH} 7.4$ phosphate buffer $0.05 \mathrm{M}$ (simulated colonic media), using the USP paddle method at $75 \mathrm{rpm}$ in a Distek Dissolution System 2100C. Samples (5 mL) were withdrawn every $15 \mathrm{~min}$ for the first hour and then every hour for a total sampling time of $12 \mathrm{~h}$. Each sample was replaced with fresh medium. Drug concentration in the samples (filtered through $0.22 \mu \mathrm{m}$ syringe filter) was determined by HPLC. Each experiment was performed by triplicate.

\section{Determination of drug concentration}

HPLC analytical methods were implemented to measure the concentration of propranolol and labetalol solutions according to the 27 USP Pharmacopeia using a Perkin Elmer 785 HPLC system equipped with a UV detector.

For propranolol a $15 \times 4.6 \mathrm{~cm}$ Supelcosil LC-8 column, $5 \mu \mathrm{m}$ particle size (Supelco) was employed. The mobile phase was sodium dodecil sulfate 0.006M:methanol:acetonitrile: $\mathrm{H}_{2} \mathrm{SO}_{4} 0.015 \mathrm{M} ; 60: 18: 18: 4$, and the flow rate was $2.0 \mathrm{~mL} / \mathrm{min}$. The wavelength was $290 \mathrm{~nm}$, injection sample $20 \mu \mathrm{L}$. For calibration, propranolol $\mathrm{HCl}$ solutions with concentration between 10 and $250 \mu \mathrm{g} / \mathrm{mL}$ were run and a linear curve with correlation coefficient of 0.998 was generated from the area under the peak measurements. The validity of the method was investigated by the determination of the precision of the assay, which was demonstrated by the coefficients of variation (CV). For concentrations $10,20,40,80,120,200,250 \mu \mathrm{g} / \mathrm{mL}, \mathrm{CV}$ for intrarun were $1.39,1.48,0.41,0.53,0.58,0.49$, and $059 \%$, respectively. The propranolol retention time was $2.1 \pm 0.1 \mathrm{~min}$.

For labetalol a 15 x $4.6 \mathrm{~cm}$ Eclipse XDB-C18 column, $5 \mu \mathrm{m}$ particle size (Agilent) was used. The mobile phase was phosphate buffer $0.1 \mathrm{M}, \mathrm{pH} 7.0$ :acetonitrile, $65: 35$, and the flow rate was $1.0 \mathrm{~mL} / \mathrm{min}$. The wavelength was $233 \mathrm{~nm}, 30 \mu \mathrm{L}$ injection volumes. Calibration generated a linear curve with a correlation coefficient of 0.997 . For concentrations of 10,50 ,
$75,120,200,250 \mu \mathrm{g} / \mathrm{mL}, \mathrm{CV}$ for intra-run were 1.69, 1.29, 1.01. $1.35,1.65,0.31$, respectively. The labetalol retention time was $3.6 \pm 0.2 \mathrm{~min}$.

\section{Conclusions}

PMAOB is an amphiphilic homopolymer, therefore composition characterization is not required and high drug loadings were obtained.

As expected for ion exchange delivery systems, the ionic strength of the media affects the rate and mechanism of release from the studied complexes.

Unfortunately a very fast release is observed for the complex of MAOB with propranolol at $\mathrm{pH} 1.2$ indicating "dumping" of the drug, which is not adequate for controlled release systems. However, drug release from PMAOB-labetalol complex is controlled at $\mathrm{pH} 1.2,6.8$ and 7.4. This complex has a great potential for sustained, near-pH independent drug release. Even when drug release occurs at $\mathrm{pH} 1.2$, the complexes fulfill the requirement for a sustained delivery system since no more than $20 \%$ of the drug is dumped in $2 \mathrm{~h}$ [26].

\section{Acknowledgements}

Work supported by SEP-CONACYT(CB-2010-1-157173).

\section{References}

1. Kanhere, S. S.; Vyas, A. H.; Bhat, C. V.; Kamat, B. R.; Shah, R. S. J. Pharm. Sci. 1969, 58, 1550-1552.

2. Moldenhauer, M. G.; Nairn, J. G. J. Pharm. Sci. 1990, 79, 659666.

3. Irwin,W. J.; Mchale, R.; Watts, P. J. Drug Dev. Ind. Pharm. 1990, $16,883-889$.

4. Raghunathan, Y.; Amsel, L.; Hinsvark, O.; Brynt, W. J. Pharm. Sci. 1982, 70, 379-384.

5. Hariharan, D.; Peppas, N. A. Proc. Intern. Symp. Control. Rel. Bioact.Mater. 1992, 19, 367-368.

6. Burke, G. M.; Mendez, R. W.; Jambhekar, S. S. Drug Dev. Ind. Pharm. 1986, 125, 713-732.

7. Nujoma, Y. N.; Kim, C. J. J. Pharm. Sci. 1996. 85:1091-1095.

8. Konar, N.; Kim, C. J. J. Pharm. Sci. 1997, 86, 1339-1344.

9. Konar, N.; Kim, C. J. J. Appl. Polym. Sci. 1998, 691, 263-269.

10. Konar, N.; Kim, C. J. J. Contr. Rel. 1999, 57, 141-150.

11. Konar, N.; Kim, C. J., in: Polymeric Drugs and Drug Delivery Systems, Ottenbrite, R.M.; Kim, S.W., Eds., Technomic, Lancaster PA, 2001, 69-85.

12. Bari, M.; Kim, C. J. Drug Dev. Ind. Pharm. 2006, 32, 531-538.

13. Lee, H.K.; Hadju, J.; McGoff, P. J. Pharm. Sci.1991, 80, 178180.

14. Khalil, E.; Sallam, A. Drug Dev. Ind. Pharm. 1999, 25, 419-427.

15. Cornejo-Bravo, J. M.; Flores-Guillen, M. E.; Lugo-Medina, E.; Licea-Claverie, A. Int. J. Pharm. 2005, 305, 52-60.

16. Cornejo-Bravo, J. M.; Partida-Soria, Y.; Serrano-Medina A.; Espinoza-Dueñas K.; Ramos M. A. Licea-Claverie A. Pharm Dev Tec. 2012, 17 170-176.

17. Chourasia M. K.; Jain S. K. J. Pharm Pharm Sci. 2003, 6, 33-66. 18. Lee, V. H. L.; Mukherjee, S. K., in: Encyclopedia of Pharmaceuti- 
cal Technology, Swarbrick, J.; Boylan, J. C., Eds., Mercel Dekker Inc., New York, 2002, 871-885.

19. Licea-Claverie, A.; Rogel-Hernandez, E.; Lopez-Sanchez, J. A.; Castillo-Arambula, L. A.; Cornejo-Bravo, J. M.; Arndt, K. F. Design. Mon. Polym., 2003, 69, 67-80.

20. Chen, Y.M.; Matsumoto, S.; Gong, J. P.; Osada, Y. Macromolecules 2003, 36, 8830-8835.

21. Inoue, T.; Chen, G.; Nakamae, K.; Hoffman, A.S. J. Contr. Rel. 1997, 49, 167-176.
22. Tarvainen, T.; Svarfvar, B.; Akerman, S.; Savolainen, J.; Karhu, M.; Paronen, P.; Jarvinen, K. Biomaterials 1999, 20, 2177-2183. 23. http://www.drugbank.ca, accessed on March, 2014.

24. Thomas, E.; Rubino, J. Int. J. Pharm. 1996, 130, 179-183.

25. Borodkin, S.; Sundberg, D. P. J. Pharm. Sci. 1971, 76, 379383.

26. Bruck, S. D. Controlled Drug Delivery, Vol. 1. Basic Concepts. CRC Press, Ed., Boca Raton FL, 1983, 150-171.

27. Ritge, P. L.; Peppas, N. A. J. Control. Rel. 1987, 5, 23-26. 